\title{
The use of sheepdogs in sheep production in southeastern Brazil
}

\author{
Rafael A. Moral', Fernando C. C. Azevedo ${ }^{2}$ and Luciano M. Verdade ${ }^{3^{*}}$
}

\begin{abstract}
This study assessed the economic value of using sheepdogs as livestock guardians in southeastern Brazil by implementing a semi-structured interview format divided into four main categories: maintenance costs of sheep production, selling prices of carcasses, annual rate of depredation, and sheepdog acquisition and maintenance costs. According to our results, producers perceive the "unproductive" costs of sheepdogs similarly to the way they view taxes. However, management using sheepdogs as herd guardians tends to be most profitable for herds above 483 head from the fourth year on, being possibly more stable and predictable over time. In contrast, management without sheepdogs shows stochastic dynamics with occasional, though unpredictable, episodes of sheep depredation. This means that sheep farmers follow a cyclical decision strategy, which basically depends on the purchase price of the sheepdog.
\end{abstract}

Keywords: Ecological management, Livestock depredation, Neotropics, Puma, Sheep industry

\section{Introduction}

Livestock predation by mammalian carnivores is one of the most common sources of conflicts between humans and wild animals worldwide (Mech 1981, Cozza et al. 1996, Kaczensky 1996, Pedersen et al. 1999, Mazzolli et al. 2002, Marchini, 2014). Most conflicts come from competition for limited resources. They may become particularly controversial when the resources concerned have economic value and the predators involved are legally protected (Thirgood et al. 2000). In Brazil, pumas (Puma concolor) have the greatest economic impact in rural landscapes (Mazzolli et al. 2002, Verdade and Campos 2004, Azevedo and Murray 2007, Palmeira et al. 2008).

Historically, conflicts with predators have resulted in predators' population decline (Weber and Rabinowitz 1996, Estes 1996, Berger et al. 2001, Krebs 2001). One of the main reasons is that most conflicts between humans and predators can be perceived in simple terms, arising from the direct effects of one predator on one prey. This can lead to the idea that a single predator directly reduces the density of prey available to humans, and

\footnotetext{
* Correspondence: Imverdade@usp.br

${ }^{3}$ Universidade de São Paulo, CENA, Núcleo Laboratorial de Ecologia Evolutiva Aplicada, P.O. Box 96, Piracicaba, SP 13416-000, Brazil

Full list of author information is available at the end of the article
}

therefore, the solution can be to remove the predators from the system (Yodzis 2001). Such culling sometimes occurs indiscriminately and affects the food web (Terborgh 1988, Hoogesteijn and Mondolfi 1992).

Depredation is influenced not only by carnivore and herd management practices, but also by habitat characteristics and the local distribution and abundance of natural prey (Polisar et al. 2003, Kolowski and Holekamp 2006). Wildlife damage could be prevented by improving livestock management, implementing alternative strategies such as greater vigilance during grazing, fencing, using sheepdogs, or returning herds to enclosures in daylight (Shivik 2006, Gehring et al. 2010a, b, Gehring et al. 2011). However, as conservation issues increasingly occupy socio-political agendas, and attitudes toward non-lethal approaches to wildlife management evolve, it is clear that a change from decisions based primarily on competition with economic interests to decisions based on the dynamic interaction between the ecosystem and socio-political system is necessary.

In such context, this study assessed the economic value of the use of sheepdogs as livestock guardians in southeastern Brazil. Sheepdogs have been historically used as a decisive strategy for livestock production, significantly reducing depredation (Coppinger and Coppinger 1980, 2007, Coppinger et al. 1987, Coppinger et al. 1988) 
and production cost (Rigg 2001, van Bommel and Johnson 2012).

\section{Material and methods}

We carried out a correlational study to determine the qualitative and quantitative effects of using sheepdogs as livestock guardians. We conducted semi-structured interviews with 29 randomly selected Brazilian farmers out of the 41 farmers attending the International Congress of Goat and Sheep Farmers (FEINCO VII), from 9 to 13 March 2010 in São Paulo, Brazil. Interview questions were divided into four main categories, each focusing on a different economic aspect of livestock management: maintenance costs of sheep production, selling price of carcasses, annual rate of depredation, and sheepdog acquisition and maintenance costs. Not all respondents provided answers to each question, and it was not possible to assess the accuracy of information provided by respondents, especially in regard to prices and costs. The participants, however, represent the views of producers themselves. All analyses were performed using the open-source statistical software R (R Core Team 2013).

Maintenance costs of sheep production were furnished by the "Associação de Caprino-Ovinocultores da Região de Piracicaba" (ACOPI), considering six months as the commercial cycle of sheep production in the centralsouthern state of São Paulo, Brazil. The price of carcasses was obtained by consulting the latest sales, as prices tend to fluctuate rapidly over time (Firetti et al. 2013). Two breeders of Maremma sheepdogs attending the Congress were consulted in regard to sheepdog purchase prices. Annual maintenance costs were estimated using information provided by breeders and users of this same breed. Provided that herds were classified into lots, each reaching the stipulated maximum of 300 head, and based on ACOPI (Grisotto 2010, ${ }^{1}$ personal communication), we assumed the use of a pair of sheepdogs per lot was sufficient, even though this number may vary depending on other factors such as the rate of depredation (Andelt 2004). To determine the importance producers assigned to depredation, in economic terms, we conducted a principal component analysis using data obtained from Question 7, which asked the respondent to classify a list of items at levels 1 to 5 , with 1 being the most important, and generated a biplot.

Depredation rates vary because it depends on several factors acting in concert, such as amount of wild versus domestic prey available (Azevedo and Murray 2007), breed and species of livestock, time of the year, species of predators in the area, location and size of the property, type of management used by the producer, presence of forest fragments nearby (Palmeira et al. 2008), and presence and abundance of predators in these areas (Polisar et al. 2003, Breck and Meier 2004).
We proposed two management models: with and without sheepdogs (respectively, Management Models I and II). Comparing both, using sheepdogs has the advantage of not losing sheep to depredation due to pumas and feral dogs, or to theft. However, there are expenses to acquiring and maintaining sheepdogs. The Management Model II does not incur these expenses, but there is a risk of depredation by wildlife and domestic dogs, and theft.

Linear correlations were established with respect to the magnitude of annual production (ranging from 15 to 2200 head) and also with respect to time, to check for patterns of stability in the economic dynamics of the producer when using different types of management. We assumed that maintenance cost were $75 \%$ of all production costs, since the maintenance cost of a sheep was estimated as USD\$ 101.18 and its selling price as USD\$ 134.91 (assuming slaughter at $40 \mathrm{~kg}$, with a carcass utilization of $50 \%$ of weight). When fitting two regression lines ( 1 and 2$)$ with different slopes, we may test for differences on estimated values $\hat{Y}_{1}$ and $\hat{Y}_{2}$, on regression lines 1 and 2, respectively, as proposed by Zar (2010, p. 353 to 369 ) to compare estimated sheep herder annual revenues, which defines the test statistic

$$
t_{c}=\frac{\hat{Y}_{1}-\hat{Y}_{2}}{s_{Y_{1}-Y_{2}}} \sim t_{n_{1}+n_{2}-4}
$$

where

$$
s_{Y_{1}-Y_{2}}=\sqrt{s_{Y . X}^{2}\left[\frac{1}{n_{1}}+\frac{1}{n_{2}}+\frac{\left(X-\bar{X}_{1}\right)^{2}}{\left(\sum x^{2}\right)_{1}}+\frac{\left(X-\bar{X}_{2}\right)^{2}}{\left(\sum x^{2}\right)_{2}}\right]},
$$

with

$s_{Y . X}^{2}=\frac{(\text { residual sum of squares })_{1}+(\text { residual sum of squares })_{2}}{(\text { residual degrees of freedom })_{1}+(\text { residual degrees of freedom })_{2}}$

\section{Results}

Interviews

We conducted interviews with 29 producers (Table 1). Sheepdog acquisition price per capita, obtained from Maremma sheepdog breeders, was USD\$ 1124.23. Maintenance costs for a six-month commercial cycle for sheep production per capita in southeastern Brazil, obtained from ACOPI, was USD\$ 101.18.

Using information from the interviews, we assumed an average of 30 head lost (ranging from 18 to 84) to depredation per year, or 2.5 head lost per month. This value was calculated taking into account the wide variability in the records of these losses, which may vary from months with no depredation to months with losses of up to 30 head on a single night. Given this variability and the 
Table 1 Mean, standard deviation, range, and sample size for number of rams and breeding ewes, annual production of lambs, ram price, carcass kilogramme price, number of sheepdogs in the farm, and annual cost of a sheepdog obtained from Questions 2, 6, 12, and 13 asked to Brazilian sheep herders during the International Congress of Goat and Sheep Farmers (FEINCO VII), held in São Paulo, Brazil, from 9 to 13 March, 2010

\begin{tabular}{|c|c|c|c|c|c|}
\hline Category & Mean & Standard deviation & Minimum & Maximum & Sample size \\
\hline Number of rams and breeding ewes & 503.4 & 597.4 & 15 & 2000 & 28 \\
\hline Annual production of lambs (head) & 432.6 & 554.7 & 15 & 2200 & 27 \\
\hline Ram price (USD\$) & 1872.67 & 1896.12 & 112.42 & 8431.70 & 27 \\
\hline Meat/carcass purchase price (USD\$/kg) & 5.17 & 1.25 & 3.93 & 8.43 & 23 \\
\hline Number of sheepdogs & 3.1 & 1.4 & 2 & 5 & 14 \\
\hline Annual cost of each sheepdog (USD\$) & 536.35 & 332.43 & 281.06 & 1236.65 & 12 \\
\hline
\end{tabular}

The answers were given in Brazilian Real, and the date of currency conversion to US Dollars was 9-3-2010 (BRL 1.00= USD\$ 1.78)

discrete nature of the random variable, a reasonable assumption is that the number of head lost annually as a consequence of depredation follows a Poisson distribution with a mean and variance of 30 per lot, as they are independent from each other.

A further point in assessing the economic consequences of livestock depredation was addressed in Question 7. From 1 (most important) to 5 (least important), according to the sheep herders, the investment required for "Food" was first (1.46), followed by "Labour" (2.07), "Veterinary/Medicine" (2.85), and "Depredation/Other", which averaged just below "Taxes", at 4.21 and 4.33, respectively. The biplot of the principal component analysis (PCA) confirmed the order of importance obtained from these means, and indicated a strong correlation between "Taxes" and "Depredation/Other" (Figure 1). PC1 explained $57.8 \%$ of the total variance and PC2 explained $28.2 \%$. It was also clear that PC1 divided, in the view of the interviewees, "productive" (i.e. food, labour, and veterinary/ medicine) costs from "unproductive" (i.e. damage and taxes) costs. PCA loadings are shown in Table 2.

Twenty-two out of 29 farmers reported damage caused by pumas (eight), feral dogs (four), theft (one), and undetermined causes (nine). Fourteen out of 29 farmers

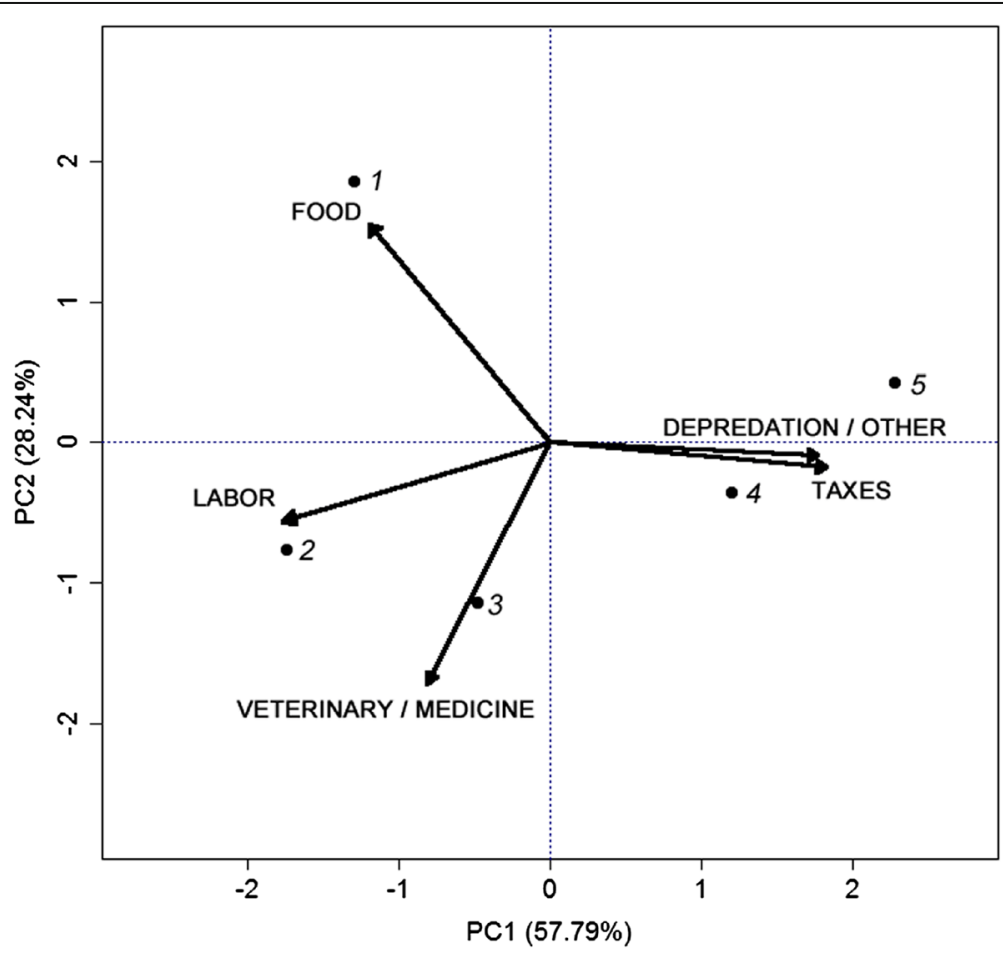

Fig. 1 Biplot of principal component analysis with correlations between items and categorizations made by interviewees from Question 7 asked to Brazilian farmers during the International Congress of Goat and Sheep Farmers (FEINCO VII), held in São Paulo, Brazil, from 9 to 13 March, 2010. This question asked the respondent to classify a list of items (food, labour, veterinary/medicine, taxes, and depredation/other) at levels 1 to 5 , with 1 being the most expensive item 
Table 2 Principal component loadings for the principal component analysis performed for the data obtained from Question 7 asked to Brazilian sheep herders during the International Congress of Goat and Sheep Farmers (FEINCO VII), held in São Paulo, Brazil, from 9 to 13 March, 2010

\begin{tabular}{llllll}
\hline Item & PC1 & PC2 & PC3 & PC4 & PC5 \\
\hline Food & -0.3480 & 0.6523 & -0.2228 & 0.3217 & 0.5481 \\
Veterinary/medicine & -0.2354 & -0.7180 & -0.3291 & 0.4903 & 0.2835 \\
Taxes & 0.5374 & -0.0737 & -0.4813 & -0.4661 & 0.5068 \\
Labour & -0.5136 & -0.2284 & 0.4473 & -0.5368 & 0.4426 \\
Depredation/other & 0.5205 & -0.0379 & 0.6406 & 0.3883 & 0.4081 \\
\hline
\end{tabular}

This question asked the respondent to classify a list of items (food, labour, veterinary/medicine, taxes, and depredation/other) at levels 1 to 5, with 1 being the most expensive item

had sheepdogs (eight Maremma, three Kuvasz, and three other breeds) with no depredation after sheepdogs' acquisition. A similar pattern has been described by Ciucci and Boitani (1998) in Italy. Among respondents who did not have sheepdogs, the main reasons for not doing so were "difficulty of training" and "high cost". In addition, one respondent reported that he had lost about 200 head in about two years (to pumas and feral dogs), and had solved the problem by installing an electric fence.

\section{Sheep management models}

Although both management models generate revenues in excess of maintenance costs of production, the costs of acquiring, maintaining, and training sheepdogs eventually generate an income approximately equivalent to losses by depredation in management systems without sheepdogs (Figure 2). The $t$ test showed that for a herd size of 483 lambs or more, revenues estimated by the linear regression curves differed significantly $\left(t_{30}=2.07, p=0.05\right)$. Thus, management using sheepdogs as herd guardians is the most profitable for herds of 483 head or more.

On the other hand, net profits from management with the use of sheepdogs (Figure 3) gradually come to exceed profits gained from management without sheepdogs. Testing differences between net revenues estimated by linear regressions showed that from the fourth year on, earnings obtained by managing the herd with the use of sheepdogs become significantly larger than earnings obtained by using the other management system $\left(t_{74}=2.70, p=0.01\right)$.

Concerning projected annual revenues for the two types of management, management with the use of sheepdogs is possibly more stable and predictable (Figure 4) and can be considered deterministic over time. In contrast, management without sheepdogs shows stochastic dynamics. This means that sheep farmers follow a cyclical decision strategy, which basically depends on the purchase price of the sheepdog. If the price is too high, then buying and maintaining them is not worth the potential costs from the loss of livestock. However, when this price drops, buying a sheepdog does compensate for potential losses.

Since the amount of losses due to depredation is not fixed and follows a Poisson distribution, and is

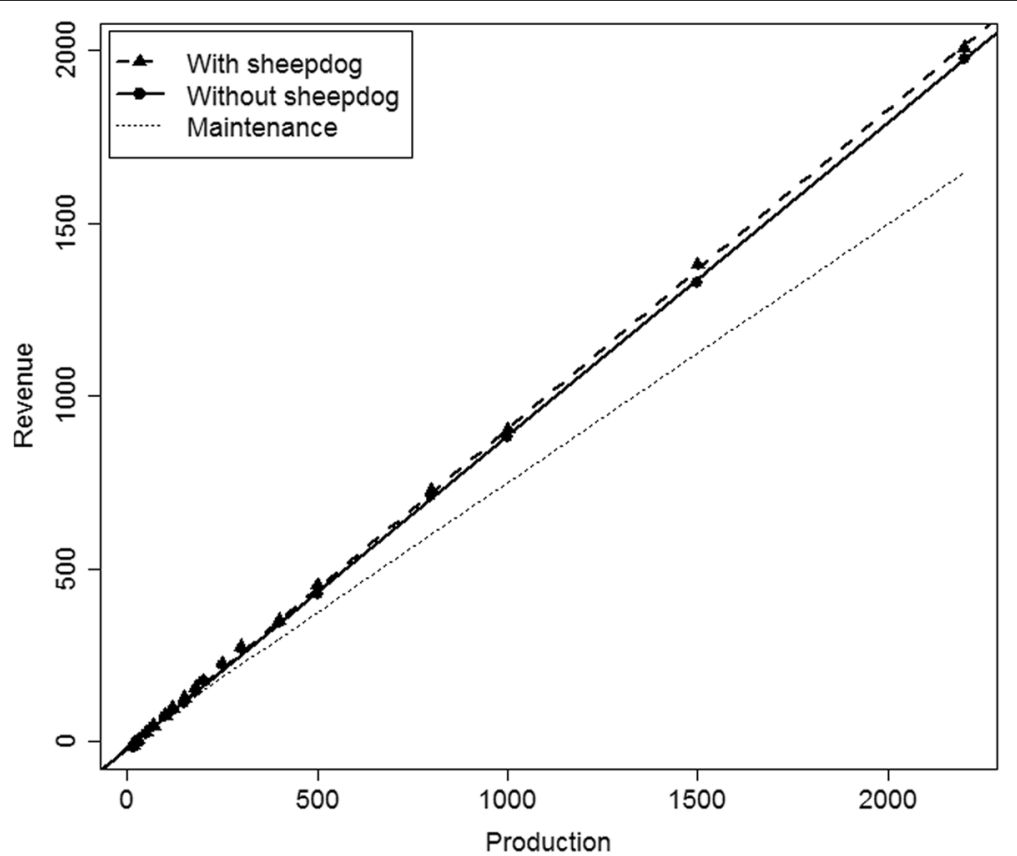

Fig. 2 Annual revenue and regression lines for the two management strategies (with and without sheepdogs) in relation to densities of production for the year of acquisition of sheepdogs. Values are given in terms of lamb production 


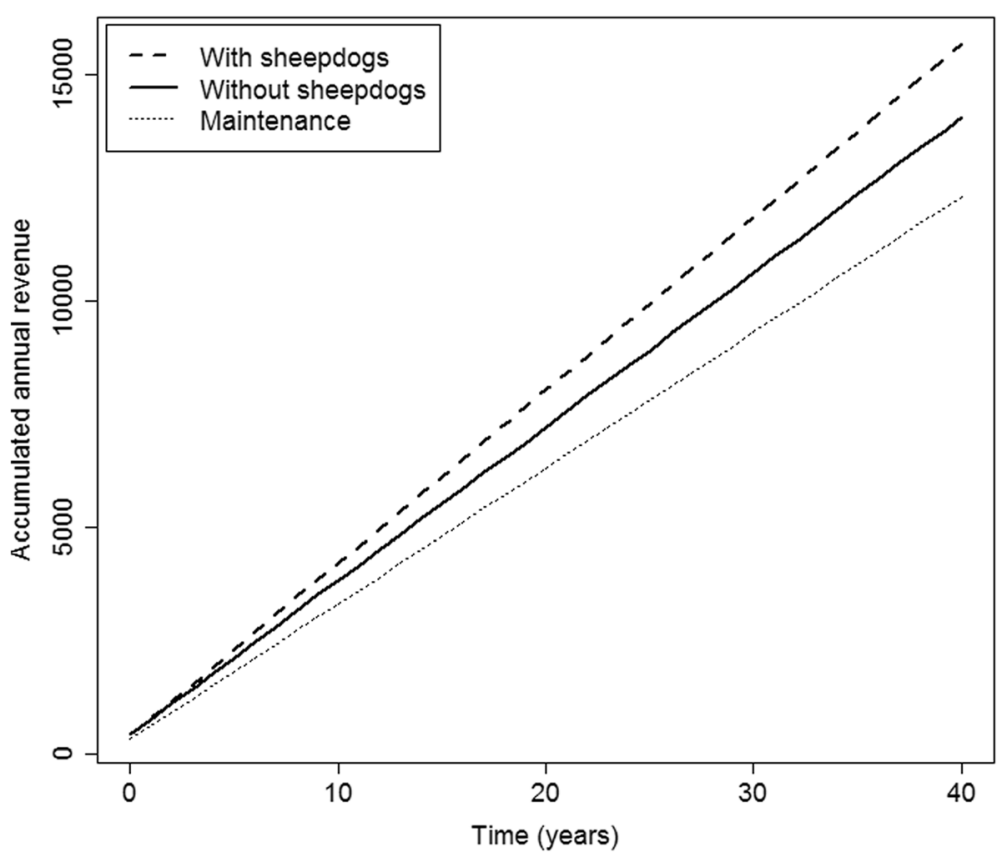

Fig. 3 Projections of cumulative annual revenues for a production of 400 head per year for 40 years after the acquisition of sheepdogs, for the two management strategies (with and without sheepdogs). Values are given in terms of lamb production

characterized as the distribution of rare events, it is possible that the model underestimates losses from management without sheepdogs. This would outweigh revenues obtained by the other strategy. It might also overestimate losses, leading to revenue levels below the break-even point. We derived the probability, obtained by the Poisson distribution, that the revenue from management without sheepdogs which will exceed the revenue from management with sheepdogs is $2.04 \times 10^{-6}$. The probability of being in the same range

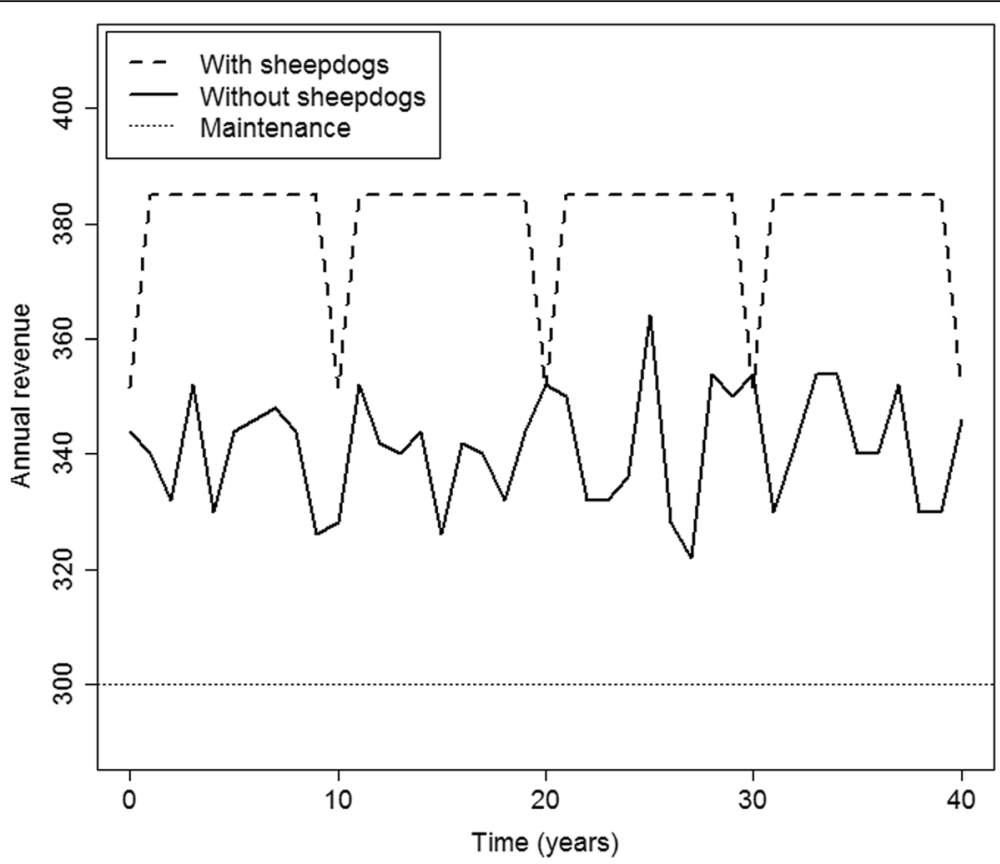

Fig. 4 Projections of annual revenues for an annual production of 400 head for 40 years after the acquisition of sheepdogs, for the two management strategies. The values are given in terms of lamb production 
as the revenue from management with sheepdogs is 0.208 , and the chance of being lower (revenue below maintenance) is $5.19 \times 10^{-4}$.

\section{Discussion}

Due to the lack of a specific public policy about wildlife damage over livestock production in Brazil, depredation often leads to retaliatory responses by producers, including persecution of carnivores, opposition to the presence of wildlife sanctuaries close to farms, or resistance to the reintroduction of extirpated predators to protected areas (Verdade 2004, Verdade and Campos 2004, Marchini et al. 2010, Marchini, 2014). Most of these retaliatory responses contravene public and political aims of large carnivore management (Graham et al. 2004).

According to our interview results, predation on the herd is less expensive than maintenance costs of the production system itself, although predators might occasionally cause serious damage (Mazzolli et al. 2002). In addition, "Depredation/Other" and "Taxes" were negatively correlated with the other factors (Figure 1) (i.e. there was a clear division between production-related costs such as food, labour, and veterinary/medicine and costs not related to production such as damage and taxes). The similarity of the factors "Depredation/Other" and "Taxes" (Figure 1) shows that, in the opinion of the interviewees, these "unproductive" costs are considered as equivalent deductions from the producer's income.

This study suggests that the revenue from the two types of management is similar (Figure 2), with a proportional increase in the amount of income earned by managing with sheepdogs over managing without them. Therefore, the use of sheepdogs to care for the herd is a cost-effective strategy as suggested by previous studies (Green and Woodruff 1980, Green et al. 1984, Andelt and Hopper 2000, Gehring et al. 2010b, Vercauteren et al. 2008, van Bommel and Johnson 2012, Rust et al. 2013). In Australia, the cost of acquiring a sheepdog is returned in up to three years (van Bommel and Johnson 2012).

Although depredation due to pumas means an instant loss for the producer (Hoogesteijn 2001), losses were not large enough to decrease overall revenues to a level below maintenance costs. Thus, both strategies can be profitable, but only one is satisfactory from the standpoint of conservation. Stability found in simulations for the scenario with the use of sheepdogs was expected, given that additional investments will be needed only for sheepdog replacement, training, and maintenance (Andelt 2004). This context was shown as sharp declines (Figure 4), but following a general pattern. This generated predictable income for the producer who includes sheepdogs in their management system.

We observed the opposite outcome for annual revenues regarding the strategy which does not use sheepdogs where peaks and valleys do not form a consistent pattern and consequently cannot be predicted as disturbances in the system (e.g. loss of a sheepdog) may occur (Marker et al. 2003, Andelt 2004). Thus, the prediction of income in these cases is merely probabilistic, and the chance that the two management schemes will provide the same income is $20.8 \%$. Deterministic processes are characterized by being predictable, so identifying and determining patterns may be, at times, easier to accomplish. On the contrary, stochastic mechanisms are governed by probabilistic processes and are, therefore, difficult to predict (Roughgarden 1998).

Two management alternatives in the present study may generate net revenues to the producer, and differ primarily in the predictability and temporal stability of income. Producers perceive the "unproductive" costs of sheepdogs similarly to their view of how taxes diminish their revenue. In being so, producers are risk takers when choosing one strategy over the other, such that the lower risk is placed on the strategy that generates a higher payoff, as they perceive it. Therefore, they tend to choose between a deterministic strategy (i.e. with the use of sheepdogs) and a stochastic strategy (i.e. without sheepdogs) which may or may not result in herd losses. A comparable behaviour has been described for tax evasion (Laffer 2004).

With respect to long-term estimates, revenue generated by the management strategy with the use of sheepdogs increases over time, in contrast to the other alternatives. Therefore, the cumulative net revenues over time increases more in the system in which sheepdogs are used (Figure 3) confirming that the benefits of using sheepdogs exceed the costs (after 40 years, the revenues are $11.57 \%$ higher than for the management without sheepdogs and $27.37 \%$ higher than maintenance costs). However, other measures (e.g. subsidies to partially fund purchase, breeding, and sheepdog sale promotions between producers, as well as non-governmental organizations actions) could be implemented to encourage farmers to use sheepdogs (e.g. Marker et al. 2003).

The use of sheepdogs by farmers should be stimulated by public policy as a least impacting livestock production management practice for wild predators as well as for benefitting the sheep production system. However, further studies regarding the longevity of sheepdogs and rates of sheep depredation by pumas and other carnivore species should be encouraged.

\section{Endnotes}

${ }^{1}$ Jaime J. Grisotto, president of ACOPI in 2010.

\section{Acknowledgements}

This study was financed by the Biota Program/Fundação de Amparo à Pesquisa do Estado de São Paulo (FAPESP) (Proc No. 2006/60954-4). The authors thank A. Carmignani, J. J. Grisotto, and R. A. Brassaloti. RAM was 
supported by FAPESP. LMV has a productivity scholarship from Conselho Nacional de Desenvolvimento Científico e Tecnológico (CNPq) (Proc. No. 309468/2011-6). The authors also thank Dr. Janet W. Reid for revising the English in the manuscript.

\section{Authors' contributions}

All authors participated in all steps of this article, from planning to data collection and analyses, and writing. All authors read and approved the final manuscript.

\section{Competing interests}

The authors declare that they have no competing interests.

\section{Author details}

'Departamento de Ciências Exatas, Universidade de São Paulo, ESALQ, P.O. Box 09, Piracicaba, SP 13419-800, Brazil. ²Universidade Federal de São João Del Rei, DCNAT, Praça Dom Helvécio 74, São João Del Rei, MG 36301-160, Brazil. ' Universidade de São Paulo, CENA, Núcleo Laboratorial de Ecologia Evolutiva Aplicada, P.O. Box 96, Piracicaba, SP 13416-000, Brazil.

Received: 4 May 2016 Accepted: 11 August 2016

Published online: 14 September 2016

\section{References}

Andelt, W.F. 2004. Use of livestock guarding animals to reduce predation on livestock. Sheep \& Goat Research Journal 19: 72-75.

Andelt, W.F., and S.N. Hopper. 2000. Livestock guard dogs reduce predation on domestic sheep in Colorado. Journal of Range Management 53: 259-267.

Azevedo, F.C.C., and L.M. Murray. 2007. Evaluation of potential factors predisposing livestock to predation by jaguars. Journal of Wildlife Management 71: 2379-2386.

Berger, J., J.E. Swenson, and I. Persson. 2001. Recolonizing carnivores and native prey: Conservation lessons from Pleistocene extinctions. Science 291: 1036-1039.

Breck, S., and T. Meier. 2004. Managing wolf depredation in the United States: Past, present, and future. Sheep \& Goat Research Journal 19: 41-46.

Ciucci, P., and L. Boitani. 1998. Wolf and dog depredation on livestock in Central Italy. Wildlife Society Bulletin 26(3): 504-514.

Coppinger, R., and L. Coppinger. 1980. Livestock-guarding dogs: An Old World solution to an age-old problem. Country Journal 7: 68-77.

Coppinger, L., and R. Coppinger. 2007. Dogs for herding and guarding livestock. In Livestock handling and transport, 3rd ed, ed. T. Granding. Oxford, England: CABI International.

Coppinger, R., J. Lorenz, and L. Coppinger. 1987. New uses of livestock guarding dogs to reduce agriculture/wildlife conflicts. Third Eastern Wildlife Damage Control Conference, 12.

Coppinger, R., L. Coppinger, G. Langeloh, L. Gettler, and J. Lorenz. 1988. A decade of use of livestock guarding dogs. Proceedings of the Thirteenth Vertebrate Pest Conference 13: 209-214.

Cozza, K., R. Fico, M.L. Battistini, and E. Rogers. 1996. The damage conservation interface illustrated by predation on domestic livestock in central Italy. Biological Conservation 78: 329-336.

Estes, J. 1996. Predators and ecosystem management. Wildlife Society Bulletin 24: 390-396.

Firetti, R., A.L.L. Alberti, and M. Zundt. 2013. Comercialização de carne ovina em cidades do interior do estado de São Paulo. Pesquisa \& Tecnologia 10(2): 1-6.

Gehring, TM, KC VerCauteren, and JM Landry 2010a. Livestock protection dogs in the 21st century: Is an ancient tool relevant to modern conservation challenges? Bioscience 60:299-308.

Gehring, TM, KC VerCauteren, ML Provost, and AC Cellar. 2010b. Utility of livestock-protection dogs for deterring wildlife from cattle farms. Wildlife Research 37:715-721.

Gehring, T.M., K.C. VerCauteren, and A.C. Cellar. 2011. Good fences make good neighbors: Implementation of electric fencing for establishing effective livestock-protection dogs. Human-Wildlife Interactions 5: 106-111.

Graham, K., P. Beckerman, and S. Thirgood. 2004. Human-predator-prey conflicts: Ecological correlates, prey losses and patterns of management. Biological Conservation 122: 159-171.

Green, J.S., and R.A. Woodruff. 1980. Is predator control going to the dogs? Rangelands 2(5): 187-189.
Green, J.S., R.A. Woodruff, and T.T. Tueller. 1984. Livestock guarding dogs for predator control: Costs, benefits, and practicality. Wildlife Society Bulletin 12: 44-50.

Hoogesteijn, R. 2001. Manual on the problems of depredation caused by jaguars and pumas on cattle ranches. New York: Wildlife Conservation Society.

Hoogesteijn, R., and E. Mondolfi. 1992. El jaguar, tigre Americano. Caracas, Venezuela: Ediciones Armitano.

Kaczensky, P. 1996. Livestock-carnivore conflicts in Europe. Munich, Germany: Munich Wildlife Society.

Kolowski, J.M., and K.E. Holekamp. 2006. Spatial, temporal, and physical characteristics of livestock depredation by large carnivores along a Kenyan reserve border. Biological Conservation 128: 529-541.

Krebs, C.J. 2001. Ecology: The experimental analysis of distribution and abundance. New York: Harper Collins College Publishers.

Laffer, A.B. 2004. The Laffer curve: Past, present, and future. Heritage Foundation Backgrounder No. 1765.

Marchini, S. 2014. Who's in conflict with whom? Human dimensions of the conflicts involving wildlife. In Applied ecology and human dimensions in biological conservation, ed. Luciano M. Verdade, Maria C. Lyra-Jorge, and Carlos I. Piña, 189-210. Heidelberg, Germany: Springer.

Marchini, S., R. Luciano, and R. Hoogesteijn. 2010. People and jaguars: A guide for coexistence. Manaus, Brasil: Amazonarium Press.

Marker, L.L., A.J. Dickman, and D.W. Macdonald. 2005. Perceived effectiveness of livestock-guarding dogs placed on Namibian farms. Rangeland Ecology and Management 58: 329-336.

Mazzolli, M. M.E. Graipel, and N. Dunstone. 2002. Mountain lion depredation in southern Brazil. Biological Conservation 105: 43-51.

Mech, L.D. 1981. The wolf: The ecology and behaviour of an endangered species. New York: Doubleday.

Palmeira, F.B.L., P.G. Crawshaw Jr., C.M. Haddad, K.M.P.M.B. Ferraz, and L.M. Verdade. 2008. Cattle depredation by puma (Puma concolor) and jaguar (Panthera onca) in central-western Brazil. Biological Conservation 141: 118-125.

Pedersen, V., J.D.C. Linnell, R. Andersen, H. Andrén, M. Lindén, and P. Segerström. 1999. Winter lynx (Lynx lynx) predation on semidomestic reindeer Rangifer tarandus in northern Sweden. Wildlife Biology 5: 203-211.

Polisar, J., I. Maxit, D. Scognamillo, L. Farrel, M.E. Scognamillo, and M.E. Eisenberg. 2003. Jaguars, pumas, their prey base and cattle ranching: Ecological perspectives of a management problem. Biological Conservation 109: 297-310.

R Core Team. 2013. R: A language and environment for statistical computing Vienna, Austria: R Foundation for Statistical Computing.

Rigg, R. 2001. Livestock guarding dogs: Their current use worldwide. IUCN/SSC Canid Specialist Group Occasional Paper No. 1. http://www.canids.org/ occasionalpapers/livestockguardingdogs.pdf. Accessed 17 July 2013

Roughgarden, J. 1998. Primer of ecological theory. New Jersey, USA: Prentice Hall.

Rust, N.A., K.M. Whitehouse-Tedd, and D.C. MacMillan. 2013. Perceived efficacy of livestock-guarding dogs in South Africa: Implications for cheetah conservation. Wildlife Society Bulletin 37: 690-697.

Shivik, J.A. 2006. Tools for the edge: What's new for conserving carnivores. Biosciences 56: 253-259.

Terborgh, J. 1988. The big things that rule the world - a sequel to E. O. Wilson. Conservation Biology 2: 402-403.

Thirgood, S.J., S.M. Redpath, D.T. Haydon, P. Rothery, I. Newton, and P.J. Hudson. 2000. Habitat loss and raptor predation: Disentangling long- and short-term causes of red grouse declines. Proceeding of the Royal Society of London B 267: 651-656.

van Bommel, L., and C.N. Johnson. 2012. Good dog! Using livestock guardian dogs to protect livestock from predators in Australia's extensive grazing systems. Wildlife Research 39: 220-229.

Vercauteren, K.C., M.J. Lavelle, and G.E. Phillips. 2008. Livestock protection dogs for deterring deer from cattle and feed. The Journal of Wildlife Management 72: 1443-1448.

Verdade, L.M. 2004. A exploração da fauna silvestre no Brasil: Jacarés, sistemas e recursos humanos. Biota Neotropica 4(2): 1-12.

Verdade, L.M., and C.B. Campos. 2004. How much is a Puma worth? Economic compensation as an alternative for the conflict between wildlife conservation and livestock production in Brazil. Biota Neotropica 4: 1-4.

Weber, W., and A. Rabinowitz. 1996. A global perspective on large carnivore management. Conservation Biology 10: 1046-1054.

Yodzis, P. 2001. Must top predators be culled for the sake of fisheries? Trends in Ecology and Evolution 16: 78-84

Zar, J.H. 2010. Biostatistical analysis, 5th ed. New Jersey, USA: Pearson Prentice Hall. 